\title{
Mapping Snap Bean Pod and Color Traits, in a Dry Bean $\times$ Snap Bean Recombinant Inbred Population
}

\author{
Christina H. Hagerty \\ Department of Botany and Plant Pathology, Oregon State University, Corvallis, OR 97331
}

Alfonso Cuesta-Marcos

Department of Crop and Soil Sciences, Oregon State University, Corvallis, OR 97331

Perry Cregan and Qijian Song

USDA-ARS Soybean Genomics and Improvement Laboratory, Beltsville, MD 20705

Phil McClean

Department of Plant Sciences, North Dakota State University, Fargo, ND 58108

James R. Myers ${ }^{1}$

Department of Horticulture, Oregon State University, Corvallis, OR 97331

\begin{abstract}
AdDITIONAL INDEX WORDS. single nucleotide polymorphism, SNP, quantitative trait locus, QTL, linkage mapping, common bean
Abstract. Snap bean (Phaseolus vulgaris L.) breeding programs are tasked with developing cultivars that meet the standards of the vegetable processing industry and ultimately that of the consumer, all the while matching or exceeding the field performance of existing cultivars. While traditional breeding methods have had a long history of meeting these requirements, genetic marker technology, combined with the knowledge of important quantitative trait loci (QTL), can accelerate breeding efforts. In contrast to dry bean, snap bean immature pods and seeds are consumed as a vegetable. Several pod traits are important in snap bean including: reduced pod wall fiber, absence of pod suture strings, and thickened, succulent pod walls. In addition, snap bean pods are selected for round pod cross section, and pods tend to be longer with cylindrical seed shape. Seed color is an important trait in snap bean, especially those used for processing, as processors prefer white-seeded cultivars. The objective of this study was to investigate the genetic control of traits important to snap bean producers and processors. RR6950, a small seeded brown indeterminate type IIIA dry bean accession, was crossed to the Oregon State University (OSU) breeding line OSU5446, a type I Blue Lake four-sieve breeding line to produce the $R R 138 \mathrm{~F}_{4: 6}$ recombinant inbred (RI) mapping population. We evaluated the RR138 RI population for processing and morphological traits, especially those affecting pods. The RR138 population was genotyped with the BARCBean6K_3 Beadchip, and single nucleotide polymorphisms (SNPs) were used to assemble a linkage map, and identify QTL for pod traits. The linkage map produced from this study contained 1689 SNPs across $1196 \mathrm{cM}$. The map was populated with an average of one SNP per $1.4 \mathrm{cM}$, spanning 11 linkage groups. Seed and flower color genes $B$ and $P$ were located on Pv02 and Pv07, respectively. A QTL for string:pod length (PL) ratio was found on Pv02 controlling 32\% of total genetic variation. QTL for a suite of important processing traits including pod wall fiber, pod height, pod width, and pod wall thickness were found clustering on Pv04 and controlled $\mathbf{2 1 \%}, \mathbf{2 6 \%}, \mathbf{1 8 \%}$, and $16 \%$ of genetic variation for each of these respective traits. A QTL for PL was found on Pv09 controlling $5 \%$ of genetic variation.
\end{abstract}

Snap bean or "green bean" is the vegetable form of common bean, and are harvested before seeds mature. Whole pods are prepared by cooking, or preserved by freezing or canning. Several pod traits are important in snap bean that differentiate them from dry bean. The most important traits in snap bean

\footnotetext{
Received for publication 22 Oct. 2015. Accepted for publication 23 Dec. 2015. We are grateful for the assistance of Randy Hopson for his expertise in managing the field plots. We thank Deborah Kean, Joel Davis, Shawna Zimmerman, Kara Young, and Annie Chozinski of the Myers vegetable breeding group for their contributions in the field, greenhouse, and laboratory. Thanks are due to Ryan Graebner for valuable discussion. This research is part of an MS thesis by C.H. Hagerty and supported by a grant from Seneca Foods Corporation. $\mathrm{CHH}$ contributed to design, conducted experiments, and drafted the manuscript. AC-M assisted CHH with linkage map construction and QTL analysis. PC and QS developed the SNP platform used in the study and conducted allele calling of SNPs. PM contributed data from the Stampede $\times$ Redhawk RI population, with physical location of SNPs and gene annotation from the Phaseolus genome sequence. JRM conceived of the project, developed the recombinant inbred population, supervised the research and assisted in writing the publication.

${ }^{1}$ Corresponding author. E-mail: james.myers@oregonstate.edu.
}

include reduced pod wall fiber, absence of pod suture strings, and thickened, succulent pod walls. Unlike dry bean pods, snap bean pods have been selected for round pod cross-section and long cylindrical seed shape.

During the first half of the 20th century, bean geneticists described several qualitative genes that affect pod shape and fiber. Tschermak (1916) followed by Lamprecht $(1932,1947)$ described $E a$ and $E b$ polymeric genes for pods with elliptical cross section vs. $e a$ and $e b$ that conditioned round pod cross section. The $E a$ and $E b$ allele series affect pod shape but are independent of pod wall fiber. In this same work, Lamprecht (1932, 1947) characterized pod wall fiber with $F a$ conditioning a pod membrane and $f a$ showing a weak pod membrane. $F b$ and $F c$ were described as modifiers of $F a$ with the genotype $f a f b f c$ having the least pod membrane. In dry pods of this allelic series, the triple recessive would show a wrinkled pod wall constricted around the seeds. The $F a-F b-F c$ series do not necessarily affect pod cross-section shape. Another polymeric set of genes (Lamprecht, 1932, 1947, 1961) include pod shape and fiber. 
These traits associated are $I a$ and $I b$, which conditioned parchmented pods with elliptical cross section vs. $i a$ and $i b$ that produced round pods with weakly expressed parchment. The stringless gene ( $S t)$ described by Prakken (1940) is unusual in that the recessive form expresses suture strings whereas the dominant allele conditions stringlessness. A second stringless gene ( $T s$ for temperature-dependent suture string formation) was described by Drijfhout (1978). He found that St-tsts is without string, $S t-T s$ - expresses incomplete string, and ststTsand ststtsts have complete string. With the exception of $S t$, none of these traits have been placed on a linkage map or have been characterized using modern molecular tools.

Seed color is an important trait in snap bean, especially those cultivars used for processing. Canners prefer white-seeded cultivars because the flavonoids present in colored seeds are water soluble and will discolor the liquor in canned green beans, or leave a colored ring where the testa is exposed in a cut bean in a frozen product (Myers and Baggett, 1999). Seed color specifications are less stringent for snap beans destined for fresh markets, and while the majority of cultivars used for fresh market have white seeds, some have colored seeds. The flavonoids that conditioning seed color have important effects on germination and emergence, resistance to pathogens, and human nutrition. White-seeded beans show reduced germination and emergence relative to their colored seeded counterparts (especially in cold and wet soils), which appears to be related to the antimicrobial properties of flavonoids (Cowan, 1999). The flavonoids in dry bean are strong antioxidants and their presence may be related to the anticarcinogenic properties of some dry bean types (Patterson et al., 2009).

Mapping phenotypic traits can give plant breeders important insight into the location of traits in a genome, which assists breeders in making targeted efforts to develop superior cultivars. Knowledge of important QTL for a given trait can help us to understand the magnitude of genetic factors and trait linkage. In addition to QTL discovery, mapping populations can serve to generate transgressive segregates. Transgressive segregates are progeny phenotypes that fall outside of parental means; these phenotypes can be very useful novel combinations of genetics that can surpass performance of parental types. We expected to see the occurrence of transgressive segregation in our study due to the nature of the inter gene pool cross used. Other evidence for transgressive segregation in interspecific crosses has been outlined in tomato [Solanum lycopersicum L. (deVicente and Tanksley, 1993)]. As those authors explain, if species carry a large frequency of complementary alleles, then crossing has the promise to create novel genotypes, including transgressive segregants. Transgressive segregation can result from complementary, additive gene action following recombination of genotypes that differ in the directionality of their antagonistic QTLs (Rieseberg et al., 2003).

Previous mapping efforts with snap bean have identified QTL for disease resistance and some pod traits. In one study, two QTL conditioning resistance to white mold in snap bean were mapped to PV06 and PV08 (Miklas et al., 2003). The QTL on PV06 was located in close proximity to the Ur-4 bean rust (Uromyces appendiculatus F. Strauss) resistance gene, and was associated with architectural disease avoidance. The QTL on PV08 was associated with increased internode length, which may prohibit use of this QTL (Miklas et al., 2003). In a wax snap bean $\mathrm{x}$ wild bean population characterized using restricted fragment length polymorphisms, pod wall fiber and suture string length cosegregated on Pv02 (Koinange et al., 1996). VandenLangenberg et al. (2012) identified QTL for pod sugar concentration, an important trait in the flavor and taste perception of snap bean. Other important snap bean pod traits such as pod wall thickness and pod cross-section shape remain to be mapped.

The objective of this study was to identify QTL associated with important processing traits in a dry bean $\times$ snap bean $R I$ population. The work of Lamprecht and others implies that several of the pod traits are under relatively simple genetic control, but we employed a quantitative approach because we generally observed continuous distributions for phenotypic variation, and were unsuccessful in determining an objective way to distribute the RI population into discrete classes.

\section{Materials and Methods}

Plant materials and trait Phenotyping. Common bean lines OSU5446 and RR6950 were selected as parents to cross and develop the RR138 RI mapping population. OSU5446 is a white-seeded bush blue lake four-sieve (80\% 1-4 sieve size pods at optimum processing maturity) green bean breeding line with type I growth habit (Singh, 1981) suitable for commercial harvest and processing. RR6950 is a Mesoamerican small brown seeded accession with type IIIA growth habit [received from J.R. Baggett (ultimate origin is unknown)]. RR6950 is not well adapted to the Pacific Northwest but is an important source of resistance to Fusarium solani (Mart.) Sacc. f. sp. phaseoli (Burk.) W.C. Snyder \& H.M. Hans. in our breeding program and has high levels of Aphanomyces eutiches f. sp. phaseoli (Pfender and Hagedorn, 1982) root rot resistance important to midwestern snap bean production. While RR6950 is of definite race Mesoamerican origin, OSU5446 was derived from the cross of 'Smilo' $\times$ 'OR91G', and as a result is likely of mixed Mesoamerican and Andean origin. The RI population used in this project was originally created to study root rot resistance (Hagerty et al., 2015), but also segregates for a range of processing traits, including PL, pod width, pod height, pod wall fiber content, and pod suture strings. The details on the development of the RI population are reported in Hagerty et al. (2015); but briefly, RR6950 was crossed as the male to OSU5446 in 2003 to produce $F_{2}$ single plants of the RR138 population, which were advanced to the $F_{3}$ generation. In the $F_{3}$ generation, $\approx$ one-quarter of the single plant families homozygous for Fin (indeterminate vine habit) were discarded, and single plants with determinate growth habit (fin) were retained from segregating families. Single plant families homozygous for Fin were discarded because essentially all contemporary snap bean cultivars are determinate to facilitate mechanical harvest. The $\mathrm{F}_{4: 5}$ generations were advanced by randomly selecting a single plant from each family. In 2008, plants within each $\mathrm{F}_{5}$ family were bulked. A total of 177 families were retained in the $\mathrm{F}_{5}$ and subsequent generations.

With the exception of pod suture strings, measurements were taken in Summer 2010 on the $F_{6}$ generation from a field trial planted at the OSU Vegetable Research Farm in Corvallis (lat. $44.571^{\circ} \mathrm{N}$, long. $123.243^{\circ} \mathrm{W}$ ) on Chehalis silty clay loam soil. Plots were $3 \mathrm{~m}$ in length, planted in a single row with 33 seeds $/ \mathrm{m}$. A single border row on the north and south sides and $1.5 \mathrm{~m}$ end plots of OSU5446 were used to minimize edge effects. Ten pods, each from a different plant, were harvested at maturity comparable to commercial harvest from each plot. Ten 
pods per genotype serve as technical replications. The first and last two plants in each plot were not used for data collection in an effort to minimize plot edge effects. Each harvested pod was then evaluated for processing traits of interest. QTL analysis was conducted using the averaged values from 10 pods.

PL was measured by gently flattening the pod against a metric ruler affixed to a clipboard; length was measured from the tip of the pod beak to the calyx attachment site. Pod height was measured from adaxial to abaxial suture and pod width was measured perpendicular to sutures, both height and width were measured using a digital caliper. Pod wall fiber was quantified by snapping the pod at the midpoint, and rating fiber strands protruding from the snapped pod on a $0-2$ scale $(0=$ no visible fiber strands, 1 = some visible fiber strands, $2=$ many visible fiber strands). Then using the snapped pod, a digital caliper was used to obtain pod wall thickness at the middle seed.

Because pod suture strings have previously been described as controlled by one or two genes (Drijfhout, 1978), strings were measured as a qualitative trait in 2010. When scored qualitatively, a deficit of stringless lines were observed and these data did not follow the expected 1:1 single gene segregation ratio $\left(\chi^{2}=110.8, P<0.0001\right)$ or a $1: 3$ two gene model with epistasis $\left(\chi^{2}=20.6, P<0.0001\right)$. Pod suture strings were rephenotyped as a quantitative trait in Spring 2013 on the $\mathrm{F}_{7}$ generation in the greenhouse at OSU. Five seeds per line were planted in a 3.78 -L pot containing commercial grade potting soil (Metro-Mix 840; SunGro Horticulture, Vancouver, BC, Canada) and thinned to three plants per pot. Supplemental plant nutrition was not used. The three most uniform pods per pot at maturity comparable to commercial harvest were gathered and total PL was measured by gently flattening the pod to a ruler attached to a clipboard. The three pods per genotype serve as technical replications, each of the three pods originated from the same pot, but different plants within the pot. To measure pod suture string length, strings were gently pulled from the calyx along the adaxial suture of the pod and detached string length was measured. String length was then calculated as a ratio of pod suture string length to total PL. Pod suture string ratio values were averaged across the three pods per line for QTL analysis. We chose to conduct analysis of suture strings as a ratio to PL so that suture string length was calibrated as a proportion of the variable PLs in the RR138 population.

Seed testa color of the RI population was phenotyped in Summer 2010 by sorting seed into three classes: white, dark brown with purple hue, and light brown with purple hue. Seed testa color of the parents was white for OSU5446 and light brown with a purple hue for RR6950, which would suggest that OSU5446 carried $p p$ and RR6950 carried PP. Because $p$ masks expression, it is not possible to know without a test cross what other seed testa color genes might be present in OSU5446. Flower color (white for OSU5446 and purple for RR6950) indicated the presence of $V$ in RR6950. RR6950 seed were shiny $(J J)$ and possessed a hilum ring $(D D)$. OSU5446 had shiny seed but $p$ masked hilum ring color. No segregation was observed for $J$ or $D$. Our working hypothesis based on knowledge of the parent's seed and flower color, and segregation among families was that the genotype for OSU5446 was ppVVbbggDDJJ and that for RR6950 was PPVVBBggDDJJ (Prakken, 1972). Such a model specifies two genes with epistasis.

DNA ISOLATION AND GENOTYPING. DNA was extracted from young trifoliate leaves in the $\mathrm{F}_{6}$ generation during 2011 using a modified cetyltrimethyl ammonium bromide (CTAB) protocol modified from Miklas et al. (1993). This protocol involves grinding leaf samples in CTAB buffer solution, chloroform:isoamyl alcohol extraction, ammonium acetate solution wash, RNase treatment, and final DNA storage in Tris-EDTA (TE) buffer for molecular marker analysis. DNA was quantified using a spectrophotometer (NanoDrop ND-1000 ultraviolet-Vis; Thermo Fisher Scientific, Waltham, MA), diluted to a final concentration of $100 \mathrm{ng} \cdot \mu \mathrm{L}^{-1}$. Fifty microliters of DNA of each genotype was sent to the U.S. Department of AgricultureAgricultural Research Service (USDA-ARS) Beltsville Agricultural Research Center (BARC) Laboratory, Beltsville, MD, where single nucleotide polymorphism analysis was run. The RR138 population was genotyped using the Illumina (San Diego, CA) BARCBean6K_3 Beadchip containing 5398 SNP markers. Access to the Illumina chip was provided through the Bean Coordinated Agriculture Project (Bean CAP, 2012). SNP genotyping was conducted at the USDA-ARS, Soybean Genomics and Improvement Laboratory, Beltsville, MD, on the Illumina platform following the Infinium HD Assay Ultra Protocol (Illumina). SNP allele calling was performed using the GenomeStudio Module v1.8.4 (Illumina). Additional SNP marker information can be found in Song et al. (2015).

LinKage MAP CONSTRUCTION, QTL ANALYSis AND STATISTICAL ANALYSIS. A linkage map was constructed using Joinmap $^{\circledR} 4$ (Van Ooijen, 2013). Raw SNP data were manually inspected in Excel (Microsoft, Redmond, WA), and SNP data with no calls and SNPs monomorphic between parents were discarded. The criteria to assess the quality of SNPs for linkage map construction were the number of missing allele calls for polymorphic loci and segregation distortion greater than 10\%. Linkage map graphics were created using MapChart 2.0 (Voorrips, 2002).

Linkage groups were detected using a logarithm of the odds (LOD) threshold of four for significant pairwise marker linkages. Other parameters included the use of Haldane's mapping function and a maximum recombination frequency of $40 \mathrm{cM}$; all other parameters were left at their default settings. QTL Cartographer (Basten et al., 2002) was used to detect QTL corresponding to the traits evaluated. Before QTL detection, the linkage map was thinned to remove cosegregating markers, thereby leaving unique markers present at $1-2-\mathrm{cM}$ intervals. QTL analysis was performed using the composite interval mapping (CIM) procedure (Zeng, 1994) implemented in Windows QTL Cartographer 1.16 (Basten et al., 2002). Up to seven cofactors for CIM were chosen using a stepwise forward and backward elimination procedure with a significance threshold of 0.1 . A scan window of $30 \mathrm{cM}$ beyond the markers flanking the interval tested was used. Genome-wise significance $(\alpha=0.05)$ likelihood ratio test thresholds for QTL identification were determined with 1000 permutations and expressed as LOD. Permutations were conducted using randomly ordered phenotypic data that followed the same distribution as the original data set were run to determine thresholds of significance.

\section{Results}

Pod AND SEED PHENOtYPIng. Most pod traits showed about normal distribution (Fig. 1). Pod suture string length exhibited a bimodal distribution, with relatively few individuals that had very short strings (Fig. 1A). As expected, OSU5446 had low string:PL whereas RR6950 had high string:PL ratio. Total PL showed the greatest transgressive 
segregation. Both parents were quite similar in length (9.4 vs. $9.5 \mathrm{~cm}$ ) but the progeny ranged from 5.5 to $12.0 \mathrm{~cm}$ (Fig. 1B). RR6950 had lower pod height and width compared with OSU5446. The progeny were about normally distributed (Fig. $1 \mathrm{C}$ and D). Pod wall thickness showed a skewed distribution with a long tail toward thicker pod walls (Fig. 1E). OSU5446 had thicker pod walls than did RR6950 although the difference was small. Both parents were similar in fiber rating (Fig. $1 \mathrm{~F}$ ), and transgressive segregation was observed among the progeny for this trait.

PL was positively and significantly correlated with pod width and pod height (Table 1.). Pod wall thickness was positively correlated to pod width, but not pod height. Pod
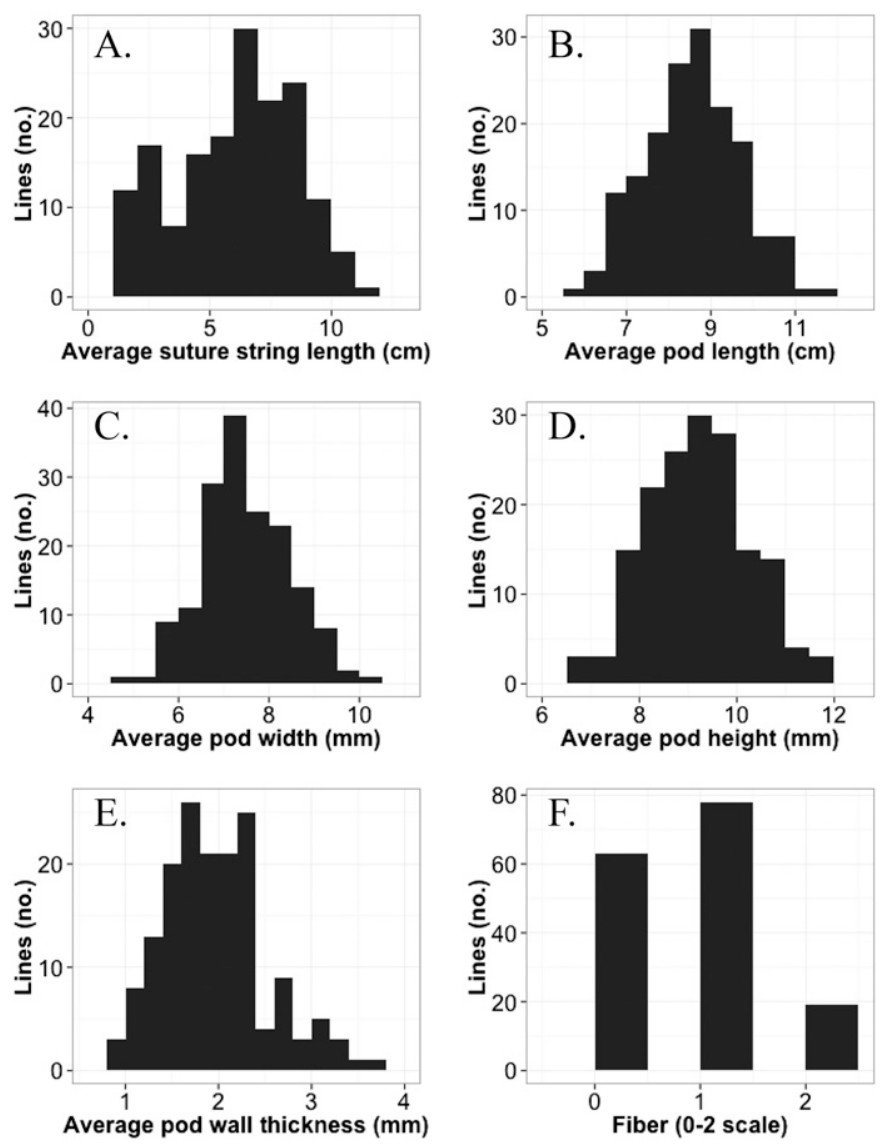

Fig. 1. Histograms of processing-related traits for the OSU5446 x RR6950 snap bean recombinant inbred population grown near Corvallis, OR. (A) Pod suture string length: OSU5446 $(2.4 \mathrm{~cm})$ and RR6950 $(7.1 \mathrm{~cm})$. (B) Pod length: OSU5446 $(9.47 \mathrm{~cm})$ and RR6950 $(9.38 \mathrm{~cm})$. (C) Pod width: OSU5446 $(8.36 \mathrm{~mm})$ and RR6950 (5.94 mm). (D) Pod height: OSU5446 (10.88 mm) and RR6950 (9.78 mm). (E) Pod wall thickness: OSU5446 (1.79 mm) and OSU6950 (1.58 mm). (F) Pod wall fiber: RR6950 (1) and OSU5446 (1).

Table 1. Pearson multiple correlation coefficients among pod traits important in processing in the OSU5446 $\times$ RR6950 snap bean recombinant inbred population grown at Corvallis, OR, in 2010.

\begin{tabular}{lcc}
\hline & Pod width & Pod ht \\
\hline Pod length & $0.219^{* * \mathrm{z}}$ & $0.288^{* * *}$ \\
Pod wall thickness & $0.396^{* * *}$ & -0.005 \\
Pod wall fiber & $0.336^{* * *}$ & $0.191^{*}$
\end{tabular}

*,**, ***Significant at $P<0.05,0.01$, and 0.001 , respectively.

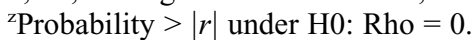

wall fiber was positively and moderately correlated with pod width but only weakly with pod height.

Seed testa color fit a 2:1:1 white: dark brown: light brown segregation ratio $\left(\chi^{2}=2.18, P=0.34\right)$ compatible with the hypothesis that the parents differed at two loci, with one locus epistatic to the other. One locus was predicted to be $P$ where colored vs. white seed segregated among lines. Within the colored class, a 1:1 segregation ratio of dark brown: light brown seed was observed, which suggested segregation at the $B$ locus.

LinkAGE MAPPING. The linkage map was previously described by Hagerty et al. (2015), but briefly, of the 5398 beadtypes, 2077 SNPs were polymorphic between the RR6950 and OSU5446 parents. SNP markers that did not appear to segregate in a 1:1 ratio $(P<0.05)$ were excluded resulting in 1689 mapped SNP markers. The resulting linkage map produced from the RR138 population was $1196 \mathrm{cM}$ in length with an average marker density of $1 \mathrm{SNP}$ for every $1.4 \mathrm{cM}$, spanning across all 11 chromosomes. Although average density was $1.4 \mathrm{cM}$, distribution across the chromosomes was uneven with some gaps approaching $50 \mathrm{cM}$. A more extensive discussion of marker distribution and the potential reasons for gaps is presented in Hagerty et al. (2015). Only linkage groups where QTL were observed are presented here (Fig. 2).

The locus associated with light- vs. dark-brown seed color $(B)$ was found at $144.9 \mathrm{cM}$ on Pv02 and cosegregated with SNP ss715644998 (Fig. 2). White vs. colored seed ( $P$ ) mapped to Pv07 at $52.0 \mathrm{cM}$.

Quantitative TRAIT LOCI. A string:PL ratio QTL was found on Pv02 controlling 32\% of total genetic variation (Table 2; Fig. 2). Although this QTL and $B$ are in the same linkage group, they are only loosely linked with a distance of $\approx 32 \mathrm{cM}$ between them. QTL for pod wall fiber, pod height, pod width, and pod wall thickness clustered together on Pv04 and controlled 21\%, $26 \%, 18 \%$, and $16 \%$ of total genetic variation, respectively. The peak for pod wall fiber was much narrower than the others. Pod height and pod wall thickness had peaks that were intermediate in width whereas the peak for pod width was the broadest (Fig. 2). The latter QTL also had the lowest LOD (7.2) of the group. A QTL for PL was found on Pv09 controlling 5\% of total genetic variation (Table 2; Fig. 2). This QTL (LOD = 4.0) was just above the LOD threshold of 3.9 for that trait.

In RI lines, the additive effect is defined as half of the difference between the parents (Cockerham, 1963). Three QTL in this study had negative additive effects, indicating that the higher values for pod suture string length, pod wall fiber, and pod height at these loci originate from RR6950 (Table 2). Three QTL in this study have positive additive effects, indicating that higher values for pod width, pod wall thickness, and PL were contributed by OSU5446.

\section{Discussion}

Pod suture strings have been the subject of genetic analysis since the beginning of the 20th century (Currence, 1930; Drijfhout, 1970, 1978; Emerson, 1904; Prakken, 1940; Wellensiek, 1922). Different models of qualitative inheritance have been proposed by different researchers. The reason for so many different genetic models is probably because the expression of strings in the pod sutures is not clearly qualitative, which may be affected by genotype and possibly environment. There does appear to be more than one locus, [one of which is temperature sensitive (Drijfhout, 1970, 1978)] and the pod 


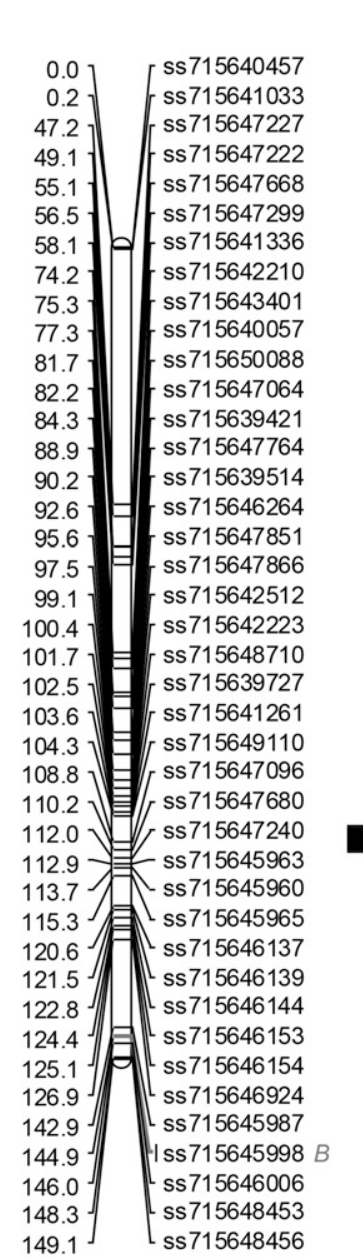

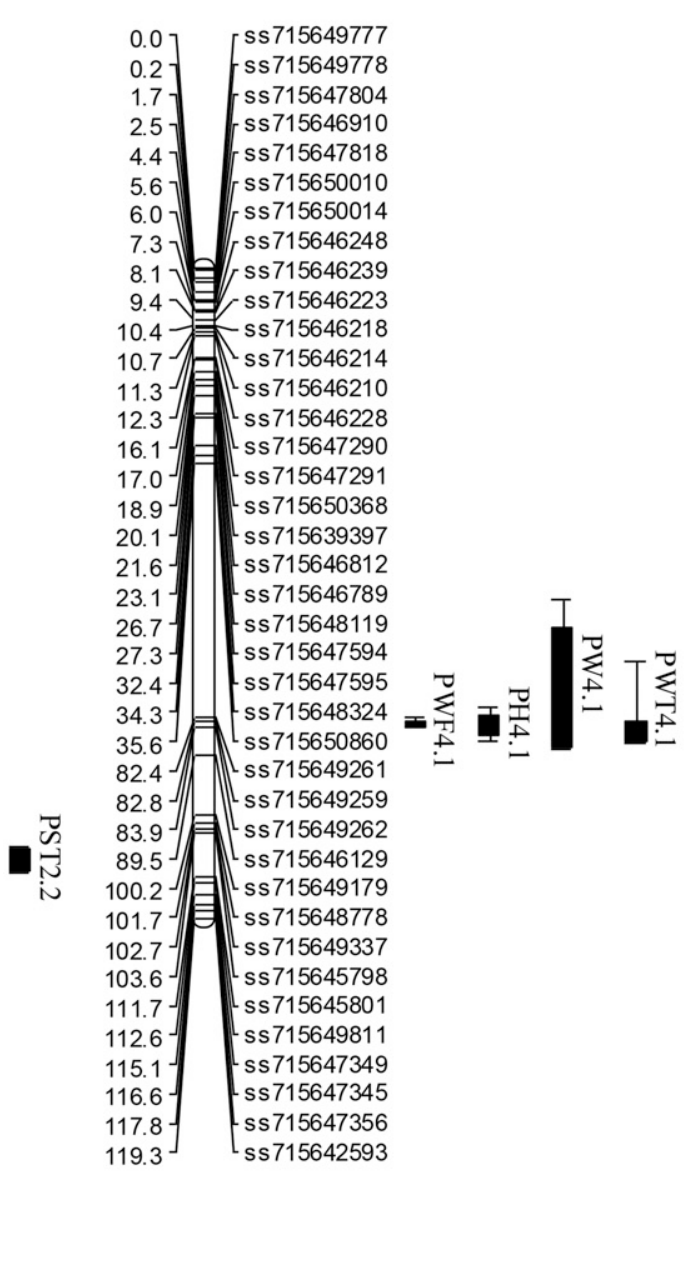

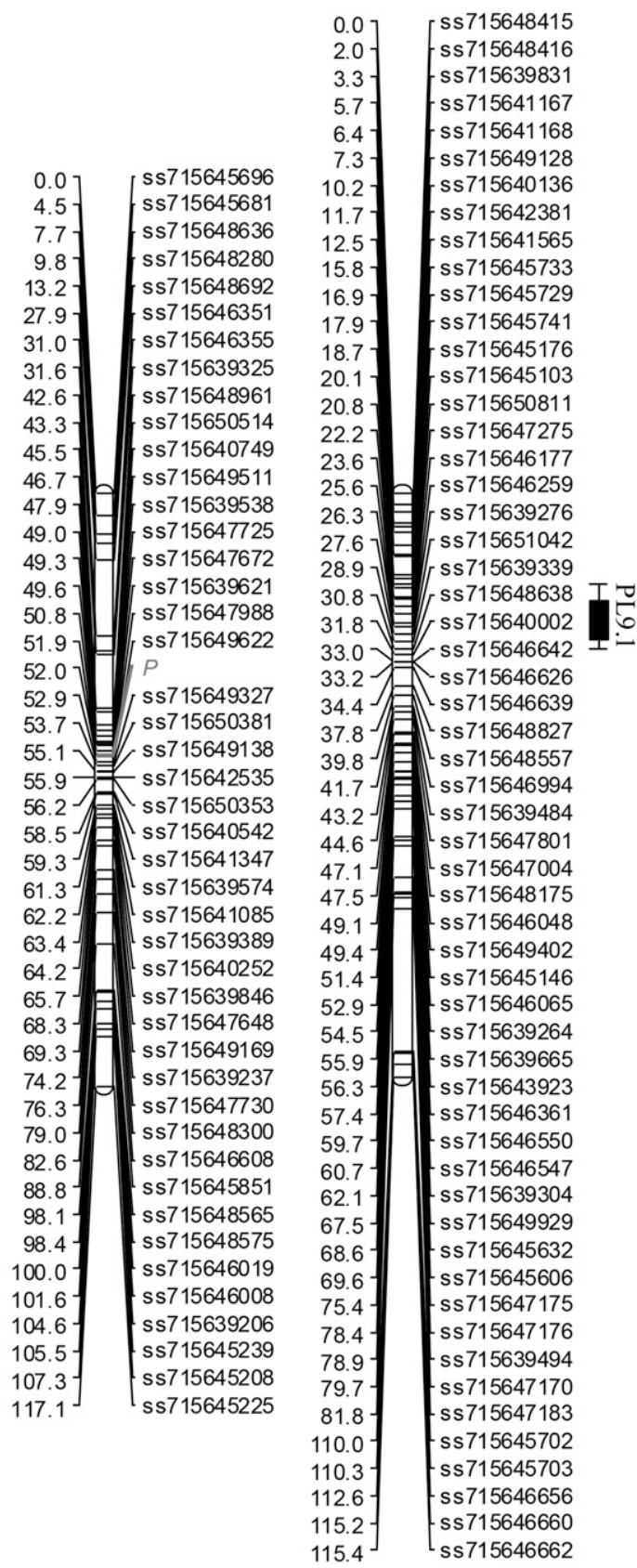

Fig. 2. Four of 11 Phaseolus vulgaris linkage groups harboring significant quantitative trait loci (QTL) and genes for processing-related traits in the OSU5446 $\times$ RR6950 snap bean recombinant inbred line population. The box delineates one-logarithm of the odds (LOD) support interval, and the whiskers of the box delineates two-LOD support interval. $\mathrm{PST}=$ pod suture strings; $\mathrm{B}=B$ color gene; $\mathrm{PWF}=$ pod wall fiber; $\mathrm{PH}=$ pod height; $\mathrm{PW}=$ pod width; $\mathrm{PWT}=$ pod wall thickness; $\mathrm{P}=P$ color gene; $\mathrm{PL}=$ pod length. Due to constraints of space, QTL are oriented in relation to the cross bars on the chromosome, not the text.

suture string trait that is most widely used commercially is controlled by a single dominant gene $(S t)$. The quantitative nature of the trait can be observed in Fig. 1A where a number of intermediate individuals were observed. The apparent bimodal distribution observed in Fig. 1A would suggest relatively simple genetic control. Even with a bimodal distribution there is enough ambiguity in various length classes to prevent accurate classification as a qualitative trait and neither $1: 1$ or $1: 3$ (stringless:stringy) ratios fit the data. We chose to use the ratio of pod suture string length to total PL as a quantitative measure of pod suture string production to compensate for differences in PL found in this population. Our rationale was that two lines might have similar pod suture string lengths, but different PLs, and could potentially be classified differently when in fact they had the same genotype at the string locus. For example, for two lines, one with $6-\mathrm{cm}$ pods and the other with $12-\mathrm{cm}$ pods, a string length of $2 \mathrm{~cm}$ would be $33 \%$ and $17 \%$, respectively, of total PL. 
Table 2. Quantitative trait loci (QTL) for green bean processing traits detected in the OSU5446 x RR6950 snap bean recombinant inbred population grown near Corvallis, OR, in 2010.

\begin{tabular}{|c|c|c|c|c|c|c|c|c|}
\hline Trait & QTL name ${ }^{z}$ & Linkage group & Position (cM) & $\mathrm{LOD}^{\mathrm{z}}$ & LOD threshold & Additive effect & $R^{2}$ & Closest SNPz \\
\hline String:PL & PST2.2 & Pv02 & 109.2 & 13.2 & 5.6 & -1.50 & 0.32 & ss 715647096 \\
\hline Pod wall fiber & PWF4.1 & Pv04 & 82.9 & 11.9 & 8.0 & -0.33 & 0.21 & ss715649259 \\
\hline Pod height & PH4.1 & Pv04 & 82.9 & 14.8 & 4.0 & -0.54 & 0.26 & ss715649259 \\
\hline Pod wall thickness & PWT4.1 & Pv04 & 83.9 & 8.5 & 4.1 & 0.22 & 0.16 & ss715649259 \\
\hline PL & PL9.1 & Pv09 & 23.6 & 4.0 & 3.9 & 0.36 & 0.05 & ss715647275 \\
\hline
\end{tabular}

${ }_{\text {zPST }}=$ pod suture strings; PWF = pod wall fiber; PH = pod height; PW = pod width; PWT = pod wall thickness; PL = pod length; LOD = logarithm of the odds; SNP = single nucleotide polymorphism.

The mapping of a QTL for string:PL produced a result similar to Koinange et al. (1996), who mapped strings as a qualitative trait $(S t)$ to $\mathrm{Pv} 02$. It is difficult to know if $S t$ of Koinange et al. (1996) and our QTL map to the same region because different marker technologies were used and these have not been integrated in a consensus map. Koinange et al. (1996) mapping population was derived from a wax snap bean $\times$ wild bean cross, and they also observed segregation for pod shatter that cosegregated with St. More recently, Gioia et al. (2013) identified PvIND, a P. vulgaris homologue of the Arabidopsis thaliana (L.) Heynh. INDEHISCENT gene and located it near St on Pv02. INDEHISCENT appears to reside within the QTL peak from our study (data not shown). Davis et al. (2006) located a QTL on Pv06 for strings in a snap $\times$ snap bean mapping population, suggesting that there may be additional loci for pod suture strings.

In addition to the difficulty in unambiguously classifying pod suture strings, there appeared to be a real deficit in the stringless class of progeny in the RI population. Others have observed similar deficits (Drijfhout, 1970, 1978). There are three possible explanations for this deficit in stringless phenotype: reduced fitness associated with the stringless allele, environmental conditions that favors pod suture fiber production in normally stringless progeny, and linkage to the Fin locus. Given the chromosomal locations of Fin and St, the latter hypothesis is not tenable. In snap peas, stringlessness is associated with reduced fitness (Myers et al., 2001) and we have noticed differences in disease susceptibility associated with fiber content in snap bean. On the other hand, a temperature sensitive gene controlling pod suture string suggests that environment can play a role in degree of string production (Drijfhout, 1970, 1978).

The length of the linkage map $(1196 \mathrm{cM})$ produced with the RR138 population is comparable to lengths reported by others but with greater marker density than previous maps created with non-SNP molecular markers (LIS, 2015). For example, Freyre et al. (1998) reported a linkage map for a consensus map of common bean of $1226 \mathrm{cM}$.

In this RI population, we purposely selected against indeterminate growth habit that is controlled by the Fin locus. This made the population easier to manage, it eliminated any interactions that growth habit might have had with other traits, and it created a population that was more relevant to the commercial snap bean industry since indeterminate types cannot be mechanically harvested. One of the consequences of this deliberate selection in the RR138 population is linkage disequilibrium on Pv01 in the region surrounding the Fin locus. As such, we were unable to map the Fin locus in our study, but it has previously been mapped to Pv01 (Blair et al., 2006;
McClean et al., 2002). Another consequence of selection for determinate growth habit is that an unknown number of genes in the region of Fin on Pv01 are represented only by the OSU5446 parent, and we may have missed mapping QTL that could be potentially located in that region.

In snap bean, pod wall fiber and pod suture fiber are separate traits, and there has been some question as to whether they are under independent genetic control. Our results would suggest that for these parents the two traits are independent because a QTL for pod suture strings was observed on Pv02 whereas a QTL for pod wall fiber appeared on Pv04. Paradoxically, the two parents had similar pod wall fiber ratings. We would have expected that pod walls of OSU5446 would have had less fiber than the walls of RR6950. The similarity in parents may have been the result of the scale employed. It was a 3-point scale and may have been too coarse to account for subtle differences in the parents. Another possibility has to do with the high frequency of reversions to high fiber pods that are observed in snap bean. These reversions occur spontaneously at rates of $0.5 \%$ to $2.25 \%$ (unpublished data), and it may have been that the OSU5446 parent used for phenotyping pod wall fiber was such a revertant.

McClean et al. (2002) used random amplified polymorphic DNA markers to map many of the color genes in common bean. Their results suggested that $B$ mapped to Pv02, but they did not find a statistically significant LOD threshold for the trait. Our results corroborate their initial findings in assigning $B$ to Pv02, although exact position cannot be compared because of differences in marker systems. Linkage between $B$ and pod suture strings on Pv02 was previously reported in the premolecular marker era by Coyne (1967) and Lamprecht (1961). Our mapping studies corroborate this finding with a linkage distance of $\approx 32 \mathrm{cM}$.

The physical location of $P$ based on our map is between the SNPs ss715649622 and ss715649327, which are at 11,251,772 and 11,388,741 base pairs (bp), respectively (see Song et al., 2015 supplemental files for physical location of SNPs). This falls within the rather broad range of 3.5 to $31.1 \mathrm{Mb}$ identified by Reinprecht et al., (2013) for the location of $P$. Moghaddam et al., (2014) recently suggested that the underlying sequence for $P$ consists of two gene models (Phvul.007G171300 and Phvul.007G171400) corresponding to an A. thaliana basic helix-loop-helix sequence and encompassing a region from $40,383,553$ to $40,397,270 \mathrm{bp}$. The $\approx 28 \mathrm{Mb}$ difference in location corresponds to $\approx 17 \mathrm{cM}$ in our map. The lack of congruency may be a result of $P$ being located in a lowrecombination region of the chromosome, which reduces the accuracy in establishing linkage distance and locus order, or there might be unusual markers present on our map that interfere with accurate map location. 
With the exception of pod suture strings, the QTL in this study are novel and have not been previously identified. PL showed positive phenotypic correlation with pod width and pod height; however, PL was not genetically correlated because it was found on Pv09, whereas pod height and pod width were observed on Pv04. Therefore, if a larger or smaller sieve size bean is desired by a breeding program, this could be achieved independently of PL. While pod wall fiber was not genetically associated with pod suture strings, it was positively correlated phenotypically and genotypically with pod width and height. Of the three genic systems describe by Lamprecht $(1932,1947,1961)$ our data best fit that of Ia Ib where fiber and pod shape show a direct relationship. However, we found only one, instead of two loci as would be predicted by Lamprecht's work.

The relationship between desirable processing traits is important to understand for breeding a commercially acceptable bean. The QTL cluster of pod wall thickness, pod height, pod width, and pod wall fiber in close proximity on Pv04 will be a useful chromosomal region for commercial breeders to target for efficiently selecting for new canning and freezing bush bean types. Given the proximity and correlation of these traits, we speculate QTL for pod wall thickness, pod width, pod height, and pod wall fiber are under similar genetic control, or are controlled by separate but linked genes. We favor the former hypothesis because changes in pod wall fiber can directly lead to differences in pod shape.

Based on the relatively few QTL that were identified for these traits, it is likely that gains would become rapidly fixed with little further gain from this cross. However, we would expect to see additional QTL from additional crossing with other germplasm, additional rounds of crossing with diverse parents could offer potential for additional gains.

In this study, we report novel QTL for PL, pod width, pod height, pod wall thickness, and pod wall fiber. We also confirm and further refine the map locations of $P$ and $B$ color genes and pod suture strings.

Because these QTL were identified using data from either a single field experiment or a single greenhouse experiment, they will need to be validated in other populations before they can be regarded with a high degree of confidence. Future studies will include linking validated QTL to selectable markers. Selectable markers for processing traits will aid in the efficiency of new cultivar development. QTL discovery and conformational studies of important traits are needed to help snap bean breeding programs produce cultivars that not only meet, but also exceed current levels of yield and stress tolerance.

\section{Literature Cited}

Basten, C.J., B.S. Weir, and Z.B. Zeng. 2002. QTL cartographer version 1.16. Dept. Stat., North Carolina State Univ., Raleigh, NC. Bean CAP. 2012. Bean CAP: A Coordinated Agricultural Project. 7 Dec. 2015. <www.beancap.org>.

Blair, M.W., G. Iriarte, and S. Beebe. 2006. QTL analysis of yield traits in an advanced backcross population derived from a cultivated Andean $\times$ wild common bean (Phaseolus vulgaris L.) cross. Theor. Appl. Genet. 112:1149-1163.

Cockerham, C.C. 1963. Statistical genetics and plant breeding: Estimation of genetic variances. Natl. Acad. Sci. Res. Council, Washington, D.C.

Cowan, M.M. 1999. Plant products as antimicrobial agents. Clin. Microbiol. Rev. 12:564-582.
Coyne, D.P. 1967. Photoperiodism: Inheritance and linkage studies in Phaseolus vulgaris. J. Hered. 58:313-314.

Currence, T.M. 1930. Inheritance studies in Phaseolus vulgaris. Minnesota Agr. Expt. Sta. Tech. Bul. 68.

Davis, J.W., D. Kean, B. Yorgey, D. Fourie, P.N. Miklas, and J.R. Myers. 2006. A molecular marker linkage map of snap bean (Phaseolus vulgaris). Annu. Rpt. Bean Improv. Coop. 49:73-74.

deVicente, M.C. and S.D. Tanksley. 1993. QTL analysis of transgressive segregation in an interspecific tomato cross. Genetics 134:585-596.

Drijfhout, E. 1970. Influence of temperature on string formation of beans (Phaseolus vulgaris). Euphytica 19:145-151.

Drijfhout, E. 1978. Inheritance of temperature-dependent string formation in common bean. Annu. Rpt. Bean Improv. Coop. 21:33-34.

Emerson, R.A. 1904. Heredity in bean hybrids. Annu. Rpt. Nebraska Agr. Expt. Sta. Lincoln, NE 17:33-78.

Freyre, R., P.W. Skroch, V. Geffroy, A.F. Adam-Blondon, A. Shirmohamadali, W.C. Johnson, V. Llaca, R.O. Nodari, P.A. Pereira, and S.M. Tsai. 1998. Towards an integrated linkage map of common bean. 4. Development of a core linkage map and alignment of RFLP maps. Theor. Appl. Genet. 97:847-856.

Gioia, T., G. Logozzo, J. Kami, P.S. Zeuli, and P. Gepts. 2013. Identification and characterization of a homologue to the Arabidopsis INDEHISCENT gene in common bean. J. Hered. 104:273-286.

Hagerty, C.H., A. Cuesta-Marcos, P.B. Cregan, Q. Song, P.E. McClean, and J.R. Myers. 2015. Mapping Fusarium solani and Aphanomyces euteiches root rot resistance and root architecture quantitative trait loci in common bean (Phaseolus vulgaris). Crop Sci. 55:1969-1977.

Koinange, E.M.K., S.P. Singh, and P. Gepts. 1996. Genetic control of the domestication syndrome in common bean. Crop Sci. 36:1037-1045.

Lamprecht, H. 1932. Beiträge zur genetik von Phaseolus vulgaris. Hereditas 16:169-211.

Lamprecht, H. 1947. The inheritance of the slender-type of Phaseolus vulgaris and some other results. Agr. Hort. Genet. 5:72-84.

Lamprecht, H. 1961. Weitere kopplungsstudien an Phaseolus vulgaris mit einer ubersicht über die koppelungsgruppen. Agr. Hort. Genet. $21: 319-332$

LIS. 2015. Legume Information System: Information about legume traits for crop improvement. 17 Dec. 2015. <http://legumeinfo.org/ chado/featuremap?name_1 $=>$.

McClean, P.E., R.K. Lee, C. Otto, P. Gepts, and M.J. Bassett. 2002. Molecular and phenotypic mapping of genes controlling seed coat pattern and color in common bean (Phaseolus vulgaris L.). J. Hered. 93:148-152.

Miklas, P.N., R. Delorme, and R. Riley. 2003. Identification of QTL conditioning resistance to white mold in snap bean. J. Amer. Soc. Hort. Sci. 128:564-570.

Miklas, P.N., J.R. Stavely, and J.D. Kelly. 1993. Identification and potential use of a molecular marker for rust resistance in common bean. Theor. Appl. Genet. 85:745-749.

Moghaddam, M.S., R. Stonehouse, R. Lee, S. Mamidi, M. Bello, P.N. Miklas, P. McClean, and K. Bett. 2014. Molecular genetic analysis of the Phaseolus vulgaris $P$ locus. Annu. Rpt. Bean Improv. Coop. 15-16.

Myers, J.R. and J.R. Baggett. 1999. Improvement of snap bean, p. 289329. In: S. Sing (ed.). Common bean improvement in the twenty-first century. Springer, Dordrecht, the Netherlands.

Myers, J.R., J.R. Baggett, and C. Lamborn. 2001. Origin, history, and genetic improvement of the snap pea (Pisum sativum L.). Plant Breeding Rev. 21:93-138.

Patterson, C.A., H. Maskus, and C. Dupasquier. 2009. Pulse crops for health. Cereal Foods World 54:108-113.

Pfender, W.F. and D.J. Hagedorn. 1982. Aphanomyces euteiches f. sp. phaseoli, a causal agent of bean root and hypocotyl rot. Phytopathology 72:306-310. 
Prakken, R. 1940. Inheritance of colours and pod characters in Phaseolus vulgaris L. Genetica 22:331-408.

Prakken, R. 1972. Seedcoat colour in Phaseolus vulgaris L.: Attempt to a general synthesis. Annu. Rpt. Bean Improv. Coop. 15:74-79.

Reinprecht, Y., Z. Yadegari, G.E. Perry, M. Siddiqua, L.C. Wright, P.E. McClean, and K.P. Pauls. 2013. In silico comparison of genomic regions containing genes coding for enzymes and transcription factors for the phenylpropanoid pathway in Phaseolus vulgaris L. and Glycine max L. Merr. Front. Plant Sci. 4:1-25.

Rieseberg, L.H., A. Widmer, A.M. Arntz, and B. Burke. 2003. The genetic architecture necessary for transgressive segregation is common in both natural and domesticated populations. Philos. Trans. R. Soc. Lond., B 358:1141-1147.

Singh, S.P. 1981. A key for identification of different growth habits of Phaseolus vulgaris L. CIAT, Cali, Colombia.

Song, Q., G. Jia, D.L. Hyten, J. Jenkins, E.-Y. Hwang, S.G. Schroeder, J.M. Osorno, J. Schmutz, S.A. Jackson, P.E. McClean, and P.B. Cregan. 2015. SNP Assay development for linkage map construction, anchoring whole-genome sequence, and other genetic and genomic applications in common bean. G3 Genes Genomes Genet. 5:2285-2290.

Tschermak, E.V. 1916. Über den gegenwärtigen Stand der Gemüsezüchtung. Zeitschrift für Pflanzenzüchtung 4:65-104.

VandenLangenberg, K.M., P.C. Bethke, and J. Nienhuis. 2012. Patterns of fructose, glucose, and sucrose accumulation in snap and dry bean (Phaseolus vulgaris) pods. HortScience 47:874878.

Van Ooijen, J.W. 2013. JoinMap 4, Software for the calculation of genetic linkage maps in experimental populations. Kyazma, Wageningen, the Netherlands.

Voorrips, R.E. 2002. Mapchart 2.0: Software for the graphical presentation of linkage maps and QTLs. J. Hered. 93:77-78.

Wellensiek, S.J. 1922. De erfelikheid van het al of niet bezit van "draad" bij rassen van Phaseolus vulgaris L. Genetica 4:443-446.

Zeng, Z.B. 1994. Precision mapping of quantitative trait loci. Genetics 136:1457-1468. 